\section{Leading from the middle: how team leaders implement lean success factors}

Team leaders implement lean success factors

\author{
Dara O. Connor
}

Enterprise Research Centre, School of Engineering, National University of Ireland Galway, Galway, Ireland, and

Kathryn Cormican

Lero - the Irish Software Research Centre, School of Engineering, National University of Ireland Galway, Galway, Ireland
253

Received 9 November 2020 Revised 1 April 2021 Accepted 13 April 2021

\begin{abstract}
Purpose - There is compelling evidence that demonstrates that organisations are failing to reap the full benefits of lean initiatives. While much work has been conducted on what factors are critical to the success of lean initiatives, there is a dearth of empirical evidence relating to whether team leaders implement critical success factors (CSFs) in practice. Therefore, this study aims to explore the extent to which functional team leaders implement lean practices focussing on the role of leadership, empowerment and culture.

Design/methodology/approach - The research analysed team leaders in a single-site manufacturing organisation. A state-of-the-art analysis was conducted to isolate relevant themes and an instrument was developed to capture data. Empirical data was collected and analysed from 34 team leaders in engineering, quality and manufacturing.

Findings - The study found that while many good managerial practices to support lean is implemented, there remain significant challenges relating to cultural issues which must be addressed. The findings illuminate a latent gap in commitment and communication from senior management, as well as an underlying discrepancy in time and resource allocation.

Originality/value - The study's findings provide new knowledge concerning the extent to which CSFs are implemented by functional team leaders in a real-world environment. The enquiry makes a valuable departure from previous research that focusses on leadership at a senior and middle manager level. It bridges the gap between academia and practice and provides tangible and concise results to management on how CSFs relating to leadership, empowerment and culture impact team leaders to drive lean methodologies.
\end{abstract}

Keywords Culture, Manufacturing, Empowerment, Leadership, Team leader, Lean success factor

Paper type Case study

\section{Introduction}

In industrialised countries, globalisation and the ever-increasing cost of production have required organisations to reassess manufacturing business models to maintain competitiveness. The overarching framework that companies leverage to achieve this goal is via the implementation of lean philosophies. Lean implementation strategies

(C) Dara O. Connor and Kathryn Cormican. Published by Emerald Publishing Limited. This article is published under the Creative Commons Attribution (CC BY 4.0) licence. Anyone may reproduce, distribute, translate and create derivative works of this article (for both commercial and non-commercial purposes), subject to full attribution to the original publication and authors. The full terms of this licence may be seen at http://creativecommons.org/licences/by/4.0/legalcode

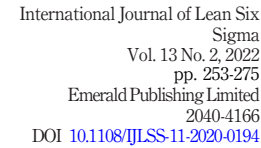


IJLSS

13,2

254

focus on ways to achieve progress while reducing waste (Antony and Gupta, 2019; Abu Bakar et al., 2015). Lean focusses on identifying where these wastes are located, as well as deploying specific tools to reduce and, if possible, eradicate them entirely (Losonci et al., 2017; Vinodh and Joy, 2012). Lean also promotes a culture of collaboration and employee empowerment at all levels to drive continuous development (Möldner et al., 2020; Taherimashhadi and Ribas, 2018).

However, prior studies indicate that organisations are still struggling to implement lean initiatives (Mostafa et al., 2013). Some scholars report failure rates as high as 90\% (Bhasin, 2012). The process of implementing a lean system into a traditional manufacturing environment is extremely challenging and requires a comprehensive cultural shift at all levels of the organisation. According to Sreedharan et al. (2020), unsuccessful implementation results in high implementation costs and employee resistance. Mostafa et al. (2013) also found that failed initiatives result in a reduction of employee confidence and poor use of resources, while Scherrer-Rathje et al. (2009) found that problems with implementation led to the termination of the lean project.

An analysis of the extant literature reveals that the reasons for failure are multifaceted and heterogeneous. For example, Psychogios et al. (2012), found that a poor understanding of the lean philosophy and the potential benefits of continuous improvement has a negative influence on lean success. Gurumurthy and Kodali (2009) found that organisations that do not adopt a holistic approach to lean are destined to fail. They note that many organisations only apply a few tools and that efforts are often incomplete and fragmented. Delgado et al. (2010) also found that companies have trouble selecting appropriate tools while Vlachos (2014) discovered that companies faced issues with the misapplication of tools. Fullerton et al. (2014) assert that lean must be implemented as a whole, rather than as an isolated business strategy. They stress that organisations must implement all the tools in the system rather than a selection. Bhasin (2012) contends that organisations must tailor their approaches to their unique context and specificities and that the approach must be viewed as a continuous journey rather than a short-term project. Seidel and Saurin (2020), also highlight the importance of context in examining lean implementation.

The state of the art provides overarching evidence to suggest that issues relating to organisational and managerial practice are essential to successful lean implementation. Several systematic literature reviews relating to lean implementation identify a comprehensive list of managerial and organisational constructs that need to be in place to be able to implement all lean practices (Antony and Gupta, 2019; Aij and Teunissen, 2017; Yadav and Desai, 2017; Yadav and Desai, 2016; Albliwi et al., 2014). These studies state that leaders' commitment and support, employee engagement, a supportive culture and appropriate infrastructure play a significant part in lean success.

It is evident that much work has been conducted to advance our understanding of lean principles and implementation practices. Nevertheless, the literature highlights three issues that limit existing research. First, prior studies provide us with a detailed and comprehensive understanding of what factors are important to lean implementation and how they relate to performance (Netland, 2016). However, they do not deduce whether or to what extent these factors are implemented in practice (Knol et al., 2018). Scholars such as Duarte et al. (2012) advocate that lean implementation success and failure depends on how and where it is applied. Seidel and Saurin (2020) and Tortorella et al. (2018) also emphasise the importance of context. Therefore, it seems that context-specific studies focussing on explaining real practices are needed.

Second, it is widely accepted that functional team leaders are responsible for the operationalisation of lean initiatives in many organisations (Coetzee et al., 2019; Tortorella et al., 2018). Functional team leaders are a conduit between the management hierarchy and the shop 
floor employees. They drive the lean methodologies championed by management to those who are most affected and arguably least accepting. Therefore, it is imperative to gain a deeper understanding of their role in the implementation process. Nevertheless, most research studies focus on a firm-level unit of analysis. This makes it difficult to understand what happens on the front line because firm-level analyses often fail to capture the perceptions and practices of team leaders on the shop floor. It seems that this gap should be addressed.

Third, effective lean implementation is clearly complex and multidimensional, incorporating many factors that impact success, such as the implementation approaches used, the tools and techniques used, as well as organisational support and managerial capabilities. Consequently, most studies adopt a broad, holistic perspective to the analysis of the critical success factors (CSFs) for lean implementation. Netland et al. (2019) assert that leadership practices are normally presented as a generic list but argue that they do not consider the unique circumstances of the different hierarchical levels of management. Psychogios et al. (2012) call for investigations to "go beyond the generic factors" towards "specific ones applied in specific contexts". Therefore, to gain a more nuanced understanding of specific salient factors it is essential to focus on a subset of factors that are most relevant to an organisation and interrogate these in more detail.

The goal of this research, therefore, is to redress the current situation and provide explanatory context-specific empirical data on the extent to which functional team leaders implement important lean practices focussing on relevant managerial and organisational constructs within a multinational manufacturing organisation. To carry out the research aims, an analysis of the literature was conducted and relevant constructs were identified and categorised. A positivist approach to data collection was adopted. To do this, a structured instrument was developed and data were collected from 34 team leaders at the coalface of manufacturing in a multinational organisation. The survey was designed to garner respondents' perceptions of the constituent elements related to CSFs identified in the extant literature, namely, leadership, empowerment and culture. Participants from three functional groups were represented: engineering, quality and manufacturing. This enabled an in-depth analysis of the data to identify underlying relationships and interdependencies from the collected responses.

Overall, the analysis highlights that while functional team leaders adopt many good lean practices relating to leadership and empowerment, there are several challenges relating to cultural issues that deserve further attention. Team leaders across manufacturing, engineering and quality feel that there are insufficient resources (e.g. time and funding) available to support effective lean implementation, there are inadequate incentives available to motivate staff and there is a dearth of cross-departmental support. The analysis also reveals that lean projects are not prioritised. The findings indicate that senior management does not prioritise communication and commitment to lean within the manufacturing group. These results emphasise the importance of these CSFs in the implementation of lean and offer practical information to organisations undergoing a shift to a lean system. The study's findings provide management with new knowledge concerning those CSFs that affect functional team leaders and, therefore contributes to a better understanding of best practice in the implementation of lean.

The remainder of this paper is organised as follows. First, a comprehensive analysis of current scholarship and debate concerning the adoption of lean practices by organisations and the specific factors that have been identified as necessary to this process are presented. Second, an overview of the quantitative methods deployed to achieve this project's main objectives and the way data was collected and analysed is provided. The study's key findings are then presented, followed by a discussion on how these findings relate to the extant literature. Finally, the paper concludes by demonstrating how this study contributes new knowledge on lean initiatives and presents some implications for future research in this area.
Team leaders implement lean success factors

255 
IJLSS

13,2

256

\section{Literature review}

An analysis of the extant literature reveals a comprehensive list of managerial aspects that need to be in place to enable the successful implementation of lean practices. For example, Yadav et al. (2017) analyse relevant frameworks and constructs relating to lean and found that leadership and top management commitment are the most used constructs. Knol et al. (2018) present a detailed list of CSFs emphasising the importance of leadership, people focus, resources, as well as communication and integration within and outside the enterprise. Psychogios et al. (2012) propose a multi-factor framework to support lean implementation that features management engagement, culture and communication-related aspects. Yadav and Desai (2017) identified 20 vital enablers to ensure an integrated lean system. Interestingly they present these enablers in a hierarchical form and discuss the relationships between them. They found that management engagement was a key enabler to facilitate activities such as strategic planning and promoting a culture of quality. Aij and Teunissen (2017) stress the importance of leaders' commitment and support, employee engagement and support infrastructure to enable lean success. Antony et al. (2014), in the context of services, found that factors such as communication, creative thinking and rewards and recognition are imperative for success. For Nguyen and Chinh (2017), leadership, organisational communication and organisational culture are factors that influence the success of the implementation. Jeyaraman and Kee Teo (2010) advocate the importance of the role of leaders (e.g. management engagement and commitment) and the role of operational infrastructure (e.g. training programmes and reward and recognition systems). Laureani and Antony (2019) found that key factors affecting lean implementation include management commitment, leadership style and cultural changes.

While it is apparent that many factors affect the implementation of lean initiatives, an analysis of the literature reveals that three key constructs emerge as being particularly important, namely, leadership, empowerment and culture. Many scholars have identified these to be most relevant to team leaders at the coalface of manufacturing (Seidel et al., 2019; Tortorella et al., 2018; Netland, 2016). Team leaders are affected by leadership (i.e. how management executes lean initiatives), empowerment (i.e. the level of engagement and ownership of the proposed processes and culture (i.e. the values, norms and support systems in place to support lean initiatives). While it acknowledged that these categories are by no means exhaustive or indeed mutually exclusive, they are clearly important to enable successful lean implementation and deserve further scrutiny. The following section synthesises the current literature and debate in the domain.

\subsection{Leadership}

The importance of strong leadership has been advocated in the literature as leaders influence other group members towards the attainment of goals and consequently, they have a major impact on lean implementation (Yadav et al., 2017; Aij and Teunissen, 2017; Jeyaraman and Kee Teo, 2010). Division of responsibility from management is one of the main premises of lean. This substantial organisational shift requires a major cultural change in the mindset of employees. A lean leader serves as the veritable link between the methodologies that the company is trying to implement and the people tasked to implement them.

Many authors speak of the importance of leaders' support and engagement in improvement activities (Netland et al., 2019; Antony and Gupta, 2019; Bortolotti et al., 2015; Dombrowski and Mielke, 2013). Berg and Black (2014) found that effective leadership is essential to foster autonomy and support the team. Scholars have found that successful lean leaders not only encourage employees to engage in the process but also to collaborate with 
other stakeholders in the process (Van Dun et al., 2016; Toma and Naruo, 2017). Pamfilie et al. (2012) assert that lean leaders' role is to delegate and motivate others to meet their goals.

Prior work has focussed on lean leadership theories and styles (Seidel et al., 2019; Tortorella et al., 2018; Tortorella and Fogliatto, 2017), lean leadership competencies (Seidel et al., 2017 Emiliani and Stec, 2004) lean leadership attributes and traits (Laureani and Antony, 2017; Aij and Teunissen, 2017), as well as leaders' actions and behaviours (Dombrowski and Mielke, 2013).

The literature on lean relating to which leadership style is best suited to lean implementation is diverse and varied. Some scholars suggest that transformational and servant leaders are relevant to lean implementation (Aij and Rapsaniotis, 2017; Assen, 2016). Transformational leaders are defined by their ability to influence engage, encourage and empower others to achieve the company's goals. Servant leaders recognise that employees are equal to themselves and work to support and enable their activities. Others believe those lean initiatives should be executed by transactional leaders in middle management ranks (Emiliani and Stec, 2004; van Dun et al., 2016). Tortorella and Fogliatto (2017) emphasise the role of situational leadership while Tortorella et al. (2018) found that a task-orientation style makes leaders more likely to achieve higher levels of success than relation-orientation style leaders.

Seidel et al. (2019) studied the relationship between seven general leadership theories and lean leadership and found that leaders' attributes, influence process and context influence the impact of lean leadership. They also suggest that lean leadership should be adapted and tailored to the specific context. For example, companies moving from a traditional manufacturing system to lean may encounter higher levels of resistance from employees and so an authentic and transformational leadership style may take priority over others in this environment.

Emiliani and Stec (2004) highlight the importance of leadership competencies. Seidel et al. (2017) studied leadership competencies that are necessary to implement and sustain lean systems. They identify 16 specific competencies and found that analytical expertise, context knowledge, leadership expertise, communication skills and project administration were amongst the most prominent. Laureani and Antony (2017) present 10 leadership characteristics that were found to be conducive to success in lean six sigma implementation, namely, visible, communicative, inspirational, consistent, targeted, leading by example, flexible, perceive lean six sigma as a philosophy, clearly define roles and responsibilities and able to build. However, Aij and Teunissen (2017) conducted a systematic analysis of lean leadership attributes and found that most studies are based on subjective assessments of behaviours and there is a dearth of empirical evidence to linking leadership attributes with organisational outcomes.

\subsection{Empowerment}

A crucial tenet in lean manufacturing is the shift in problem-solving and decision-making responsibilities from supervisors and quality departments to individual workers and teams. Consequently, the role of employee empowerment has been widely advocated in the literature as an essential factor for effective lean implementation (Bellisario and Pavlov, 2018; Alagaraja and Egan, 2013). Empowerment, while often considered to be difficult to define, refers to the idea of devolving power and control towards the employee so that they engage closely with the work and take ownership of their decision-making. Empowerment involves providing employees with the opportunity, freedom, self-confidence, knowledge, skills and resources to manage themselves. This devolution of responsibility is, therefore, at
Team leaders implement lean success factors 
IJLSS

13,2

the heart of lean culture and offers the reduction of bureaucracy and the promise to solve problems quickly and efficiently.

Prior work has investigated this construct in some detail. For example, HernandezMatias et al. (2019) examined the relationship between empowerment and performance and Roslin et al. (2018) studied the impact of employee involvement and empowerment on lean outcomes. Many scholars have found that empowerment leads to better engagement and ownership in lean initiatives (Albrecht and Andreetta, 2011; Antony et al., 2007). Selfdetermination has been found to help employees to experience meaning, control and efficacy in their roles. Accordingly, it is often linked to employee satisfaction (Bellisario and Pavlov, 2018; Jadhav et al., 2014; Antony et al., 2007). It is also lauded to facilitate decentralisation and task autonomy (Moyano-Fuentes and Sacristan-Diaz, 2012), flexible organic structures (Jayaram et al., 2008) and foster a culture of responsibility at all levels. Yadav and Desai (2017) found that employee empowerment helps to attain effective cross-functional management and they also provide evidence to demonstrate that empowerment leads to effective communication, which, in turn, supports improved quality information and analysis.

Employee empowerment can be considered in terms of a fundamental mindset that needs to be created by management to generate proactive behaviours. Management must cede power and control to their employees and equip them with the skills and autonomy needed to make informed decisions. Practices to enable empowerment to provide a mechanism to engage employees in lean implementation by encouraging them to take ownership of the process and responsibility for their activities. According to Jadhav et al. (2014), management must motivate employees to get involved in lean implementation, empower them to make decisions and remove any obstacles that interfere with the process.

However, transitioning to this way of working presents some significant cultural challenges and requires particular attention by team leaders on the shop floor. Organisations that wish to foster employee empowerment must not only encourage their employees to take initiative to improve processes but must also support them in their endeavours. Clear goals, the ability to make informed decisions about work practices and fair reward and recognition systems are necessary. Fullerton and McWatters (2002) list nine specific elements necessary to enable the shift to employee empowerment: e.g. standardisation, manufacturing cells, reduced set-up times, kanban system, one-piece flow, reduced lot sizes, reduced buffer inventories, 5s and kaizen. Melton (2005) notes that these practices involve a top-down transfer of responsibilities and are necessary to support the lean philosophy. In many circumstances, it is the team leaders that oversee this process and are at the forefront of these significant aspects of organisational change necessary for lean implementation.

\subsection{Culture}

The importance of culture is widely cited in the literature as a key success factor to lean implementation (Ahmad et al., 2017; Losonci et al., 2017; Aij and Teunissen, 2017). Some researchers have found that culture has an impact on lean production (Bortolotti et al., 2015; Losonci et al., 2017), while others have found that a culture supporting performance improvement efforts, was important to both the individual employee (Alagaraja and Egan, 2013), as well as the organisation (Moyano-Fuentes and Sacristan-Diaz, 2012). Pamfilie et al. (2012) maintain that a lean-conducive organisational culture is fundamental to the adoption of lean practices. Bhasin (2012) argues that successful lean implementation is dependent on pervasive cultural transformation at all levels of an organisation's structure. 
Antony and Gupta (2019) found in a structured review of the literature that a positive culture was imperative for successful lean implementation. They argue that a culture of continuous improvement is essential as lean is based on the principle of continuous improvement towards achieving perfection in operations. Psychogios et al. (2012) highlight the importance of a quality-driven organisational culture for lean success. In fact, organisational culture is central to their framework for lean implementation. They found that a high level of awareness of the importance of quality was essential to transition towards a lean mindset. More specifically, the shift towards effective supplier relations, improvement of the information flow and knowledge management, internal processes efficiency level and employees' qualifications and acceptance of the changes were the most CSFs to promote a quality-driven culture. Bortolotti et al. (2015) found that organisations that demonstrate higher institutional collectivism, future orientation, a humane orientation were more successful when implementing lean than those who do not.

Scholars claim that organisations must engage the workforce to create a culture that promotes lean improvement. According to Jadhav et al. (2014), this involves mentoring people and enabling them to analyse and resolve root causes of problems. However, they also warn that creating a lean enterprise requires a significant change in culture, habits, attitude of employees and management. It is widely acknowledged that the transformation of pre-existing organisational identity into a new established organisational mental model is very challenging. This happens because teams tend to rely on inherited habits and routines to solve problems.

Transitioning to a lean culture, therefore, requires proactive decision-making and enhanced responsibilities. Consequently, it is to be expected that management of an established industrial firm may face deeply entrenched attitudes that resist the changes towards greater efficiency that lean techniques require. It is important to note that resistance to change is a natural tendency for most people. People do not like to move out of their comfort zone and employees are no exception. Lean implementation requires a change in attitude and culture. Pepper and Spedding (2010) argue that management may fail to fully grasp the ethos of lean and focus more on tools and practices instead of building the lean philosophy from the bottom-up. Team leaders, at the forefront of lean implementation, play an essential role in the process of cultural change.

\section{Methodology}

Figure 1 explains the research process used in this study. The first stage involved a comprehensive analysis of current scholarship and debate concerning the adoption of lean practices and the identification of specific managerial success factors that have been

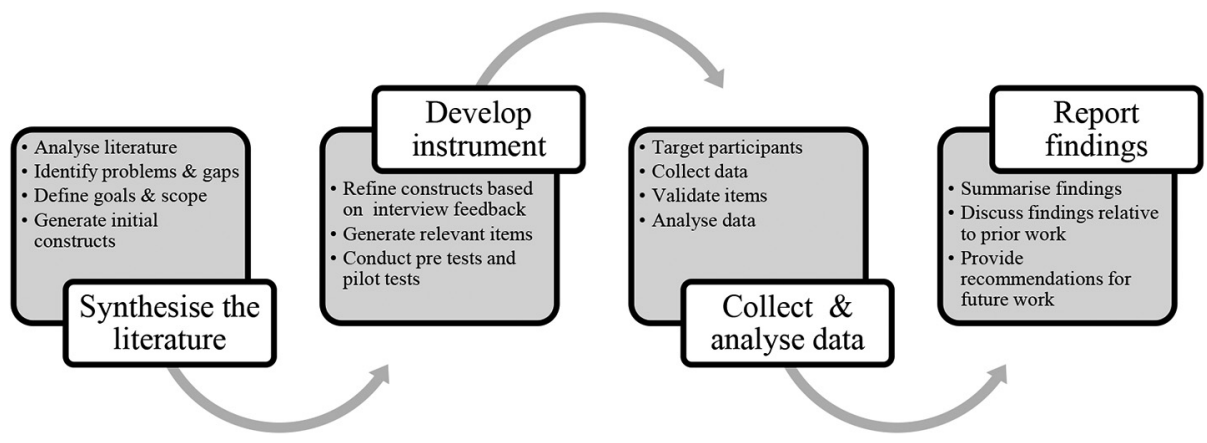

Figure 1. Overview of the research process 
IJLSS

13,2

identified as necessary to this process. Research gaps and problems were generated, prioritised and refined and focussed research goals were developed. The most relevant CSFs for the successful implementation of lean were then identified. These constructs were verified with the case organisation to ensure that they aligned well with the specific context and refined accordingly based on feedback from this process.

The second stage in the process involved the development of a structured instrument to collect data to garner the perceptions of respondents relative to the constituent elements concerning the CSFs identified in the extant literature. The approach taken to developing the instrument was based on the advice of DeVellis (2012). The questionnaire used in this study was divided into two sections. The first section focussed on capturing critical information regarding the team leaders who chose to participate in this study. The next sections focussed on the three CSFs, i.e. leadership, empowerment and culture. Items were derived following the themes detailed in the prevailing literature. Every item was carefully designed (and refined through an iterative process) to measure specific elements of each parent factor following good practice (Corry and Cormican, 2019; Cormican and O'Sullivan, 2004). A fivepoint Likert scale response system, ranging from strongly disagree to strongly agree was used to measure the extent to which respondents agreed with each item (Table 1).

Before issuing the survey, pre-test meetings were conducted with team leaders and subject matter experts to assess the survey's content. The objective of these interviews was to ensure that the most relevant factors were included from an industry perspective and that any errors were eliminated. These activities helped to assess the validity of the content and ensured adequate coverage. The instrument was also pilot tested with five representatives of the sample population. The survey questions were then amended based on feedback from these tests. The leadership subscale consisted of nine items $(\alpha=0.796)$, the empowerment subscale consisted of eight items $(\alpha=0.772)$ and the culture subscale consisted of eight items $(\alpha=0.858)$, thus demonstrating high levels of internal consistency. Next empirical data was collected from the participants and the data was analysed systematically. Care and attention were given to the nature of statistical tests used to ensure that they aligned with the goals of the study and that they adhered to good data analysis protocols. The findings were summarised and the results were discussed relative to the extant literature. Finally, limitations to the method were defined and recommendations for future research directions were provided. In the following sections, further information on the targeted participants and how the data was analysed is provided.

\section{Results}

\subsection{Participants}

The target population for this study was functional team leaders who implement lean initiatives daily. These people are responsible for driving lean philosophies and implementing lean methodologies within their associated teams. The sampling frame consisted of all team leaders or leaders who have a significant influence on teams involved with implementing lean initiatives. To avoid bias, managers and industrial engineers whose remit consists solely of propagating lean philosophies were omitted from the target population. Systematic random sampling was chosen as the most appropriate sampling method. In total, 79 questionnaires were issued and 34 were collected. Table 2 shows the profile of participants in our survey.

\subsection{Data analysis}

A normality test was conducted to determine whether the significance levels of the sample data collected fitted a normal distribution; a Mann-Whitney $U$ test was performed to 


\begin{tabular}{|c|c|c|c|}
\hline Construct & Items & $\begin{array}{l}\text { Cronbach's } \\
\text { alpha }\end{array}$ & implement \\
\hline Leadership & $\begin{array}{l}\text { 1. I provide guidance to my team members in relation to implementing lean } \\
\text { initiatives } \\
\text { 2. I actively encourage my team to constantly improve their lean skills and } \\
\text { knowledge } \\
\text { 3. I ensure my team engages accordingly with all cross-functional stakeholders } \\
\text { 4. I provide honest constructive analysis in relation to lean initiatives being } \\
\text { driven by my team } \\
\text { 5. I actively work with my manager in relation to the prioritisation of lean } \\
\text { projects developed by my team } \\
\text { 6. I feel I possess the necessary skills to provide direction to my team in } \\
\text { terms of using lean tools and techniques } \\
\text { 7. The senior management team provides me with the time and resources to } \\
\text { drive lean projects on the manufacturing shop floor } \\
\text { 8. Senior management actively encourages the implementation of lean } \\
\text { methodologies on the manufacturing shop floor } \\
\text { 9. I feel confident in the senior management team's commitment to lean } \\
\text { methodologies in relation to driving the organisation forward }\end{array}$ & 0.796 & 261 \\
\hline Empowerment & $\begin{array}{l}\text { 10. I support my team members to take responsibility and drive lean initiatives } \\
\text { 11. I provide adequate time for my team to work on lean projects } \\
\text { 12. I allow my team members scope to develop creative lean initiatives } \\
\text { 13. I ensure that successful lean initiatives implemented by my team } \\
\text { members are communicated to management } \\
\text { 14. I feel my team receives the appropriate recognition for implementing } \\
\text { lean methodologies } \\
\text { 15. I feel that the company provides sufficient incentives to engage in lean } \\
\text { initiatives and projects } \\
\text { 16. I feel that by driving lean philosophies on the manufacturing shop floor } \\
\text { that we are helping to secure the company's future } \\
\text { 17. I feel that I get adequate support from other departments in relation to } \\
\text { implementing lean projects }\end{array}$ & 0.772 & \\
\hline Culture & $\begin{array}{l}\text { 18. The organisation actively promotes a culture of lean and problem- } \\
\text { solving on the manufacturing shop floor } \\
\text { 19. I feel that the senior management team promote a culture of cross- } \\
\text { departmental integration in relation to lean projects and initiatives } \\
\text { 20. The organisation provides adequate training and development schemes } \\
\text { for employees in relation to lean tools and techniques } \\
\text { 21. The organisation provides adequate time for my team to work on lean } \\
\text { projects } \\
\text { 22. The organisation provides sufficient funding for lean projects developed } \\
\text { by my team } \\
\text { 23. The organisation communicates how lean initiatives at the operations } \\
\text { level link to the customer } \\
\text { 24. The organisation communicates how lean initiatives at the operations } \\
\text { level link to vendors and suppliers } \\
\text { 25. The organisation communicates how lean initiatives at the operations } \\
\text { level link to the overall company strategy }\end{array}$ & 0.858 & $\begin{array}{r}\text { Table } 1 . \\
\text { Constructs and items }\end{array}$ \\
\hline
\end{tabular}

determine the difference between the agree and disagree results on the subscales; and a Kruskal Wallis $H$ test was conducted to compare the difference amongst three functional groups (engineering, manufacturing and quality) concerning the implementation of lean practices relating to leadership, empowerment and culture. Finally, a Pareto analysis was 


\begin{tabular}{|c|c|c|c|c|}
\hline \multirow{5}{*}{$\begin{array}{l}\text { IJLSS } \\
13,2\end{array}$} & Characteristics of participants & $(\%)$ & Characteristics of participants & $(\%)$ \\
\hline & Functional departments & & Level of lean experience & \\
\hline & Manufacturing & 44.1 & Expert & 0 \\
\hline & Quality & 29.4 & Proficient & 41.2 \\
\hline & Engineering & 26.5 & Moderate & 55.9 \\
\hline \multirow{2}{*}{262} & Others & 0 & Low & 2.9 \\
\hline & Work experience & & Team size & \\
\hline Table 2. & Less than 1 year & $\begin{array}{l}11.8 \\
147\end{array}$ & $\begin{array}{l}1-5 \\
6-10\end{array}$ & $\begin{array}{l}44.1 \\
20.6\end{array}$ \\
\hline Profile of & At least 3 years but less than 5 years & 20.6 & $11-15$ & $\begin{array}{r}20.0 \\
5.9\end{array}$ \\
\hline participants in our & At least 5 years but less than 10 years & 20.6 & $16-20$ & 0 \\
\hline survey & 10 years or more & 32.4 & 21 or more & 29.4 \\
\hline
\end{tabular}

conducted to provide an accurate cumulative representation of the answering pattern for each survey question, as well as to identify the extent to which key success factors are implemented in practice.

4.2.1 Test of normality. This study used Kolmogorov-Smirnov and Lilliefors test, to determine whether the significance levels of our data collected fitted normal distribution. Test results show that the values of skewness and kurtosis of all the questions are not close to zero and the $p$-values are all less than 0.01, which means that the data does not fit the normal distribution. Consequently, non-parametric tests were used to analyse data in this study.

4.2.2 Mann-Whitney $U$ test. The Mann-Whitney $U$ test used in the non-parametric analysis was used to determine the difference between the agree and disagree results. Following the work of Hung et al. (2005), data were categorised into two groups: Group 1 consisted of strongly agree and agree on responses; group 2 consisted of neutral, disagree and strongly disagree responses. A Mann-Whitney $U$ test was then performed (Table 3). $p$-values of variables (leadership, empowerment and culture) are all 0.000 , which means group 1 and group 2 have statistically significant differences. The percentage of subjects expressing strongly agree and agree on practices relating to leadership and empowerment $73.53 \%$ and $82.35 \%$, respectively. This indicates that functional team leaders implement good practices relating to leadership and empowerment in this sample. However, the percentage of subjects expressing strongly agree and agree on practices relating to culture is only $55.88 \%$ suggesting there are some issues relating to cultural practices that need to be addressed.

4.2.3 Kruskal Wallis H Test. Kruskal Wallis $H$ test is a non-parametric statistical method for testing and comparing the differences between three or more independently sampled groups. It extends the Mann-Whitney $U$ test that can only test differences between two

Table 3.

Results of Mann-Whitney $U$ test

\begin{tabular}{lcrcrcccr}
\hline Var. & Group & $n$ & $(\%)$ & $\begin{array}{c}\text { Mean } \\
\text { rank }\end{array}$ & $\begin{array}{c}\text { Sum } \\
\text { of ranks }\end{array}$ & $\begin{array}{c}\text { Mann- } \\
\text { Whitney U }\end{array}$ & $Z$ & $p$-value \\
\hline Leadership & 1 & 25 & 73.53 & 21.86 & 546.5 & 3.570 & -5.028 & 0.000 \\
Empowerment & 2 & 9 & 26.47 & 5.39 & 48.5 & & & \\
& 1 & 28 & 82.35 & 20.50 & 574 & 0.000 & -4.360 & 0.000 \\
Culture & 2 & 6 & 17.65 & 3.50 & 21 & & & \\
& 1 & 19 & 55.88 & 24.11 & 458 & 17.000 & -4.520 & 0.000 \\
& 2 & 15 & 44.12 & 9.13 & 137 & & & \\
\hline
\end{tabular}


independent groups. This study used the Kruskal Wallis $H$ test to determine if there is a difference amongst three functional groups (engineering, manufacturing and quality) regarding the extent to which they implement good practices relating to leadership, empowerment and culture to support lean. The results are shown in Table 4 . As illustrated, the $P$-value of the total influence is 0.037 , which implies that there are significant differences amongst these three groups regarding the implementation of good practices relating to leadership, empowerment and culture. Engineering reported higher levels of implementation (median $=3.84$; mean rank $=22.89$ ), followed by quality groups (median = 3.64 ; mean rank $=19.80$ ) and manufacturing groups (median $=3.29$; mean rank $=12.73$ ). Interestingly, our results also show that the difference between these three groups is significant regarding the extent to which practices relating to empowerment are implemented $(p=0.043)$.

Further analysis of the results reveals that the manufacturing group responded differently from the quality and engineering groups concerning the amount of time they provide their team to implement lean initiatives, the level of training offered by the organisation to their employees concerning lean tools and techniques and the amount of recognition provided to their team to acknowledge their efforts. While most respondents in the engineering and quality groups believe that these practices were implemented, respondents from the manufacturing cohort did not. Their scores suggest that teams in manufacturing receive the insufficient time, training and recognition to work on lean projects. The manufacturing cohort also perceived senior managements' commitment and encouragement towards lean differently from those in engineering and quality. Overall, the negative responses to the two questions posed in the survey (items 8 and 9) were not troublingly high. However, of the total respondents who negatively responded, $66 \%$ were from the manufacturing group. The results also reveal that while all respondents from the engineering cohort noted that they ensure that successful lean initiatives implemented by their team members are communicated to management, however, the quality and manufacturing group did not concur to the same extent.

4.2.4 Pareto analysis. To provide an accurate cumulative representation of the answering pattern for each survey question and to ascertain the most influential practices, the data were interrogated via Pareto analysis. This technique is ideally suited to quantitative data and was used in this study to succinctly garner a holistic understanding of the scoring arrangements for each item or question. Table 5 shows the results. In this table, occurrences of agree results, representing the frequency of the agree responses (consisting of

\begin{tabular}{llrccr}
\hline Var. & Groups & $n$ & Median & Mean rank & $p$-value \\
\hline Total & Engineering groups & 9 & 3.84 & 22.89 & 0.037 \\
& Manufacturing groups & 15 & 3.29 & 12.73 & \\
Leadership & Quality groups & 10 & 3.64 & 19.80 & 0.067 \\
& Engineering groups & 9 & 3.89 & 22.50 & 13.23 \\
Empowerment & Manufacturing groups & 15 & 3.33 & 19.40 & 0.043 \\
& Quality groups & 10 & 3.61 & 22.67 & \\
Culture & Engineering groups & 9 & 3.88 & 12.87 & 0.063 \\
& Manufacturing groups & 15 & 3.20 & 22.06 & 13.07 \\
& Quality groups & 10 & 3.75 & 20.05 &
\end{tabular}

Team leaders implement lean success factors

263

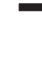




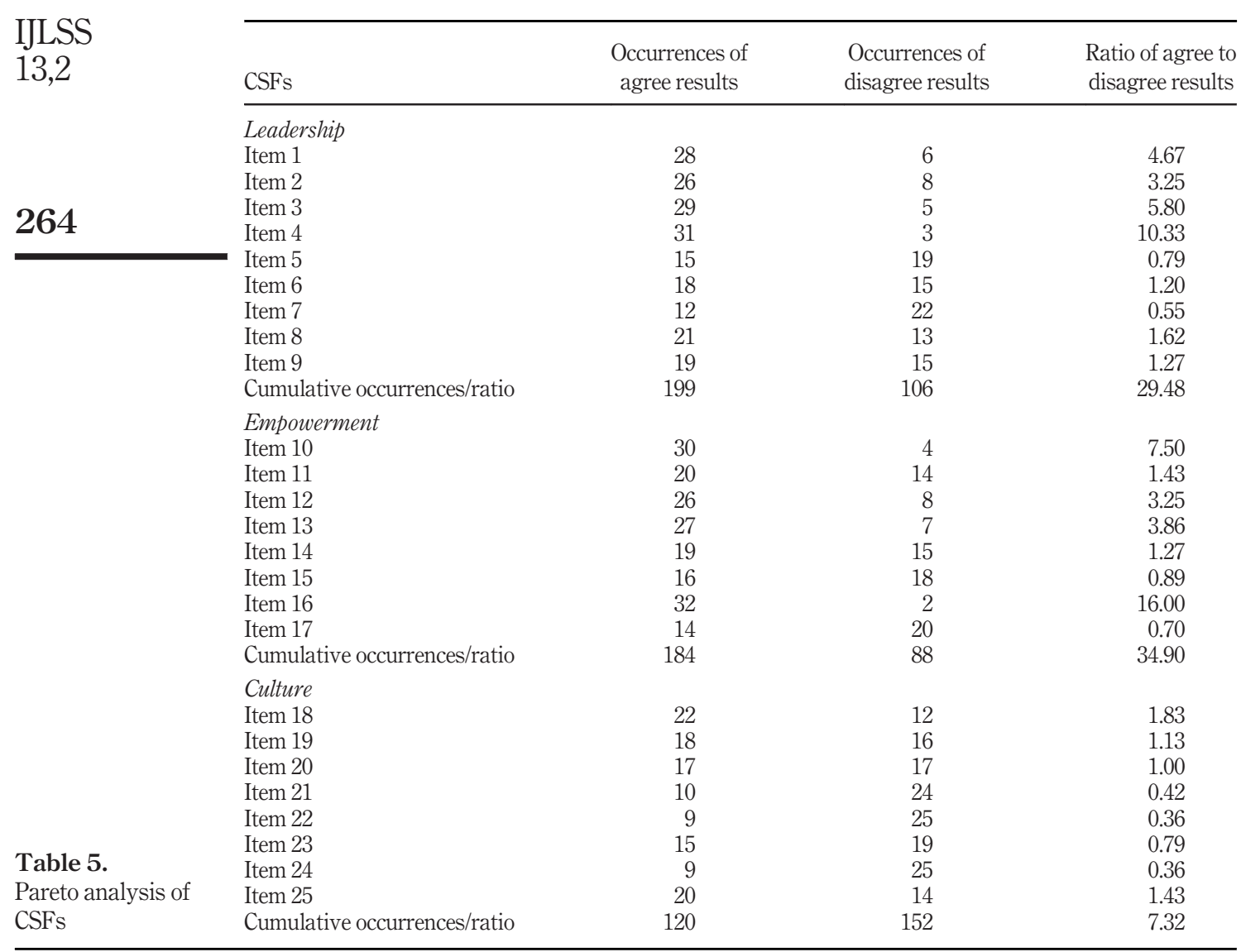

agree and strongly agree responses), occurrences of disagrees, representing the frequency of the digress responses (consisting of neutral, disagree and strongly disagree responses), as well as the ratio of agrees to disagree are reported.

As shown in Table 5, the largest cumulative ratio between agree to disagree results relating to empowerment (34.90) indicating that there no substantial discrepancy between the number of respondents who agree and disagree. The ratio between agree and disagree pertaining to leadership (29.48) is slightly lower than empowerment. However, the ratio between these categories in culture (7.32) is the lowest one which means that there is divided opinion between respondents who agree and disagree regarding the implementation of factors relating to culture. Furthermore, for culture, the cumulative occurrence of disagree results is larger than the agree results. These results suggest that while participants in our sample implement good practices that affect leadership and empowerment, there is divided opinion relating to practices implemented to support the cultural infrastructure in the organisation. The results suggest that there are concerns relating to the level of time and funding provided for lean projects and the nature of communications relating to how lean initiatives at the operations level link to vendors and suppliers. To further identify and 
analyse influential factors, a more detailed analysis using Pareto plots with 80/20 rules was used in our research. The details are discussed below.

As discussed above, it is suggested that the implementation of practices relating to leadership is essential to the success of lean implementation. The Pareto plot for leadership (Figure 2) provides us with a more detailed understanding of the specific factors related to leadership that is implemented in practice. Based on the 80/20 rule, the most influential practices are clearly identified. For example, team leaders report to provide honest constructive analysis concerning lean initiatives driven by their team, ensure their team engages accordingly with all cross-functional stakeholders and provide guidance to their team members concerning implementing lean initiatives. However, the results suggest that the senior management team does not provide team leaders with the time and resources to drive lean projects on the manufacturing shop floor. Furthermore, team leaders feel that they do not work with their managers concerning the prioritisation of lean projects developed by their team.

Similarly, a detailed analysis using a Pareto plot for empowerment was conducted. As illustrated in Figure 3, most respondents feel that they are helping to secure the company's future by driving lean philosophies on the manufacturing shop floor. They support their team members to take responsibility for and drive lean initiatives and they also ensure that successful lean initiatives implemented by their team members are communicated to management. However, they reported that they do not receive sufficient support from other departments concerning implementing lean projects and that the company does not provide them with sufficient incentives to engage in lean initiatives and projects.

Finally, the Pareto plot for culture is illustrated in Figure 4. This shows that the ratio of agree to disagree is much smaller than those relating to leadership and empowerment
Team leaders implement lean success factors

265

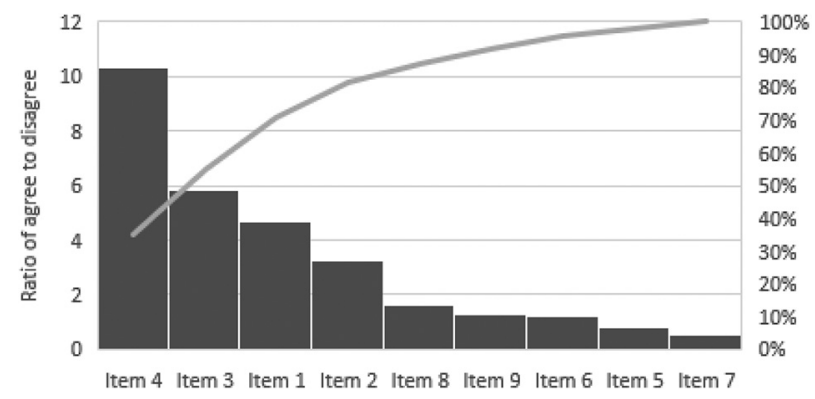

Figure 2.

Pareto plot for leadership

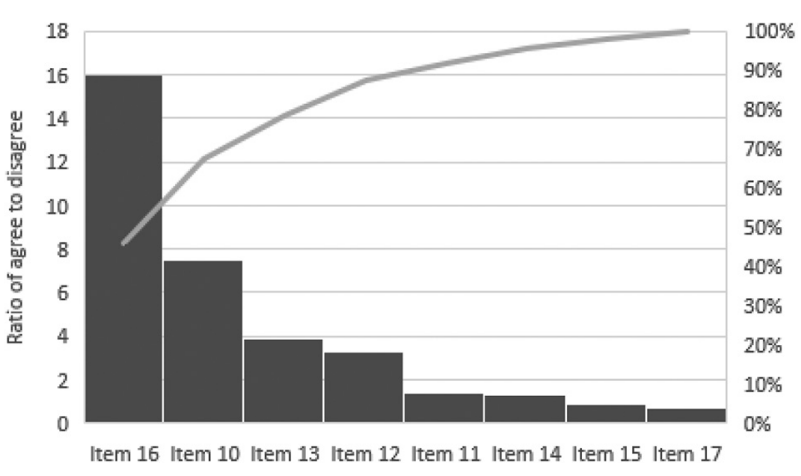

Figure 3. Pareto plot for empowerment 


\section{IJLSS \\ 13,2}

\section{6}

Figure 4.

Pareto plot for culture

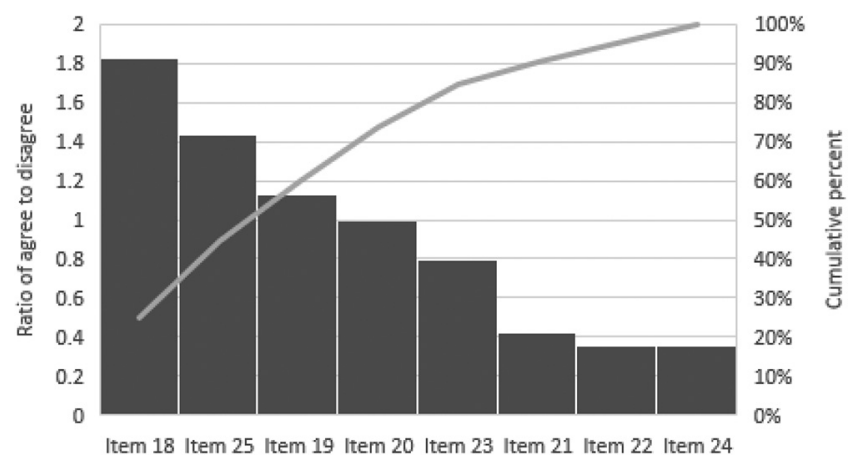

ranging from 0.36 to 1.83 . This demonstrates a difference of opinion concerning CSFs implemented to enable culture and indicates that many respondents do not believe that cultural practices are well executed. The results suggest that the organisation promotes a culture of lean and problem-solving on the manufacturing shop floor and it communicates how lean initiatives at the operations level link to the overall company strategy. However, they also suggest that many key enablers to support a lean culture are not in place. For example, the respondents believe that the organisation does not provide sufficient time and funding for lean projects developed by the team and the organisation does not communicate how lean initiatives at the operations level link to vendors and suppliers. Furthermore, it is believed that there are inadequate training schemes for lean tools and techniques available to employees.

\subsection{Summary of findings}

In this section, a summary of the key findings from this study is presented. Overall, the findings from the analysis offer an intriguing insight into how team leaders from functional groups perceived each of the questions relating to the CSFs (leadership, empowerment and culture) and how they drive the implementation of lean methodologies in a manufacturing context. The findings suggest that functional team leaders implement many good practices relating to leadership and empowerment in this sample. However, there are some issues relating to cultural practices that need to be addressed. These issues centre on support allocated to the implementation of lean initiatives (e.g. time and funds), communication (e.g. how lean initiatives at the operations level link to vendors and suppliers) and training in lean tools and techniques.

Under the category of leadership, it was discovered that constructive analysis, team engagement and guidance play important roles in the implementation of lean techniques. However, functional team leaders believe that senior management does not provide them with sufficient time and resources to drive lean projects on the manufacturing shop floor. Furthermore, the findings reveal that team leaders do not work with their managers concerning the prioritisation of lean projects.

Similarly, under the category of empowerment, the results suggest that there is overwhelming support for lean thinking and team leaders believe that they are helping to secure the company's future by driving lean philosophies on the manufacturing shop floor. Team leaders support the team members to take responsibility and drive lean initiatives and ensure that successful lean initiatives implemented are communicated to management. 
However, respondents report that there is insufficient support from other departments and insufficient incentives provided by the company to engage in lean initiatives and projects.

In terms of culture, the findings confirm that there are some positive practices relating to culture in place. Most notably, team leaders report that the organisation actively promotes a culture of lean and problem-solving on the manufacturing shop floor. They also assert that the organisation communicates how lean initiatives at the operations level link to the overall company strategy. However, respondents highlight issues relating to resources. The findings suggest that the organisation does not provide sufficient time or funding to work on lean projects. Furthermore, while the organisation communicates how lean initiatives at the operations level link to the customer, they do not communicate how these initiatives link to vendors and suppliers.

It is also important to note that these factors were not implemented universally across the functional groups analysed. The analysis revealed that there are differences amongst the three groups (engineering groups, manufacturing groups and quality groups) regarding the implementation of CSFs relating to lean. The engineering group report higher levels of good practice implementation followed by the quality group and the manufacturing group. The following section provides a more in-depth discussion of these significant findings and what they mean to organisations undergoing the process of transitioning to lean initiatives.

\section{Discussion}

Here, a discussion of the results is divided into three sections based on each of the CSFs at the centre of the research: ownership and employee empowerment, leadership and culture.

\subsection{Leadership}

Effective leadership is lauded to be one of the most critical elements when developing a lean thinking organisation (Seidel et al., 2019; Netland et al., 2019; Tortorella et al., 2018; Yadav et al., 2017). The implementation of lean methodologies requires major change and, in turn, major change demands more leadership. Moreover, while lean leadership is important at all levels of the organisation (Antony and Gupta, 2019; Albrecht and Andreetta, 2011), Netland et al., 2019 argue that leaders must adapt practices to their hierarchical levels. Therefore, it seems pertinent to explore the extent to which functional team leaders implement good practices in some detail.

Dombrowski and Mielke (2013) assert that lean leaders must ensure that all employees are fully engaged and involved in lean improvement activities. Prior work also advocates that lean leaders must motivate (Pamfilie et al., 2012) and support (Berg and Black, 2014) their team. Lean leaders should not only encourage employees to engage in the process but also collaborate with other stakeholders in the process. For example, Psychogios et al. (2012) found that considering internal customers in lean initiatives has a major impact on organisational performance. Yadav and Desai (2017) also acknowledge the importance of collaborating with other stakeholders in the process. They note that effective communication between the departments builds the organisational quality culture. The findings from this current analysis suggest that functional team leaders emphasise good practices to help influence, motivate and enable others to do their job by providing detailed feedback and promoting cross-functional integration.

However, it is apparent that functional team leaders face some challenges too. The findings suggest that, counter to good practice, senior management does not provide functional leaders with the time and resources necessary to execute lean projects on the shop floor. Timans et al. (2012) found that insufficient resources to support the effective implementation of lean was a key inhibitor to success. Albliwi et al. (2014) also noted that a
Team leaders implement lean success factors 
IJLSS

13,2

lack of resources is a major barrier to successful lean implementation. Furthermore, functional leaders in this current study reported that they do not work with their managers to prioritise lean projects developed by their teams. Netland (2016) speaks about the importance of project prioritisation and advocates a structured approach to lean project prioritisation and Albliwi et al. (2014) found that poor project selection had a negative impact on lean performance. Therefore, it seems that if senior management is to commit to a lean philosophy, they must endeavour to support it adequately. It is expected but not sufficient to encourage lean initiatives. Senior management must also enable their execution.

This current study found that the perceptions placed on management commitment and support were not uniform across the functional groups surveyed. Manufacturing team leaders identified weaknesses in management's commitment and encouragement towards lean. These results suggest that senior management may prioritise core activities such as production output over initiatives such as lean. This is, perhaps, an issue that deserves further exploration, as it points towards a senior manufacturing management mindset that advocates a traditional manufacturing model which is counter to lean principles.

The respondents from the manufacturing group also noted that the organisation does not provide adequate training and development schemes for employees concerning lean tools and techniques. However, prior research suggests that adequate training and education are essential to the successful implementation of lean (Albliwi et al., 2014; Jeyaraman and Kee Teo, 2010). This is an issue that requires further investigation, as manufacturing leaders are responsible for one of the largest groups of employees. For example, $80 \%$ of the respondents who indicated that they did not possess the necessary skills were responsible for teams with 21 or more members.

\subsection{Empowerment}

Studies by Hernandez-Matias et al. (2019) and Roslin et al. (2018) highlight the importance of employee empowerment concerning the successful implementation of lean. This is particularly applicable for the employees who work in manufacturing, as they are in direct contact with both the product and process. This current study indicates that CSFs relating to ownership and employee are implemented in practice. Participants from all three functional groups (engineering, quality and manufacturing) firmly believe in the benefits of lean and its impact on the organisation's performance. They unequivocally contend that they support their team members to take responsibility and drive lean initiatives. They also ensure that they communicate lean successes to senior management.

These findings support those found in previously published studies. For example, Psychogios et al. (2012) found that a positive disposition towards the lean philosophy and an understanding of the potential benefits of continuous improvement is important to lean success. Hu et al. (2015) recommend that employee empowerment should be integrated into lean implementation plans. While Scherrer-Rathje et al. (2009) stress the importance of effective organisational communication when adopting a bottom-up approach to implementing lean.

However, participants in this study assert that they do not receive adequate recognition or incentives for the efforts they invest in lean implementation. This was most prominent in the manufacturing cohort. Al-Balushi et al. (2014) noted recognition as one of the essential characteristics for lean practice implementation. Many other scholars also emphasise the importance of rewards and recognition to enable successful lean implementation and to avoid the potential negative effect to motivation that can result from not adequately rewarding team members (Yadav and Desai, 2017; Antony et al., 2014; Jeyaraman and Kee Teo, 2010). A possible explanation for this result could be that generally, the manufacturing 
group has less technical input to lean projects than engineering or quality. Consequently, engineering and quality would receive higher plaudits for executing the more technical aspects of the project.

The manufacturing group also highlighted a lack of support from other departments regarding the implementation of lean projects. This is a concern as previous research has identified the importance of strong cross-functional integration in the success of transformational programmes (Yadav and Desai, 2017; Mostafa et al., 2013). It seems that stronger interdisciplinary integration is necessary. For instance, Jadhav et al. (2014) found that cross-functional teams are important in lean implementation as many of the issues relating to lean implementation departmental boundaries.

\subsection{Culture}

Organisational culture is continuously highlighted as an essential factor for successful lean implementation in the extant literature (Sreedharan et al., 2020; Aij and Teunissen, 2017; Dombrowski and Mielke, 2013). For example, Sreedharan et al. (2020) stress the importance of a positive culture and infrastructure development for effective lean deployments. Psychogios et al. (2012) proposed a model supporting lean implementation that emphasises the importance of organisation culture. While Nguyen and Chinh (2017) and Dombrowski and Mielke (2013), found that organisational culture is a salient factor that influences the success of lean implementation. Notably, Pamfilie et al. (2012) found that culture is the most fundamental success factor to effective lean adoption. However, despite its importance, culture is also lauded to pose the greatest challenge to lean implementation (Melton, 2005). According to Hines et al. (2004), management may oftentimes struggle to alter the culture at the manufacturing shop floor level as this ultimately involves a complete upheaval of work practices from the traditional manufacturing model.

In this study, the responses relating to the implementation of CSFs for culture were mixed. Many respondents felt that cultural enablers were not deployed. The questions posed concerning culture and organisational change related to how the participants perceived the organisation's commitment, communication and overall structural supports towards lean implementation at their level. Many respondents agreed that the organisation actively promotes a culture of lean and problem-solving on the manufacturing shop floor. The organisation communicates how lean initiatives at the operations level link to the overall company strategy and the senior management team promotes a culture of crossdepartmental integration concerning lean projects and initiatives.

However, it seems that while senior management encourages and promotes lean initiatives it seems that they do not support or enable them. Most respondents assert that the organisation does not provide sufficient time or funding for lean projects. This deficit needs to be addressed. If organisations want to transition to a lean organisation, then the appropriate infrastructure must be in place to support and enable the move. The implementation of lean initiatives is thorny, complex and prone to failure, therefore every effort should be made to ensure that sufficient resources are in place to facilitate and enable the successful implementation of lean.

\section{Contributions, limitations and future research \\ 6.1 Contribution}

This study is a unique academic inquiry into the extent to which CSFs for lean are implemented in a manufacturing environment. The findings make a timely and necessary contribution to the current discussion and debate in several ways. First, our study provides a more nuanced understanding of what occurs in a real-world setting. Specifically, it

Team leaders implement lean success factors

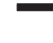


IJLSS

13,2

examines the extent to which managerial and organisational constructs are implemented in practice. The results suggest that team leaders do not or cannot place importance on all factors equally. Some practices are emphasised over others. Furthermore, not all functional groups implement practices uniformly. For example, this study found that some functions (e.g. manufacturing) differed from others (e.g. engineering and quality) in the nature and extent of how CSFs are deployed. Further confirmation in longitudinal studies notwithstanding, these findings can help to advance the body of knowledge into the nature of success factors, and thus contributes to the existing literature.

Second, the unit of analysis in this study focusses on the role of functional team leaders which seems to be neglected by the current literature. This cohort is not an expert in lean, but they are tasked to execute lean initiatives. They provide an invaluable bridge between senior management and the shop floor and they play a significant role in the adoption of complex management practices. The decision to focus on these team leaders was a strategic one. While there is extensive prior academic research and debate concerning the importance of leadership at the senior and middle manager level regarding the implementation of lean, there is a dearth of studies focussing on leadership at the coalface of manufacturing. By prioritising team leaders at this level, this study addresses this gap and is a much-needed contribution to current research and practice on lean implementation.

Third, this study also makes a methodological contribution. The constructs and items defined in this study were found to be both valid and reliable. This provides the mechanism for future researchers to test these constructs in other settings (e.g. healthcare, education and retail) and to compare the findings to this study and others. This would enable a deeper and richer discussion on the mechanics and insights of lean implementation in context-specific environments and help to address some of the concerns raised by scholars.

This study has some managerial implications that should also be emphasised. First, new and tangible insights for managers in the process of shifting from the traditional manufacturing model at the shop floor level towards that of a lean philosophy are provided. The results of this study can help them focus on those specific managerial areas that enable the implementation of lean practices. More specifically, the three constructs for analysing lean leadership may offer a practical framework for practitioners interested in developing lean leadership. The early identification of how these three constructs manifest in practice allows for proactive and theoretically grounded managerial behaviours and actions, such as the role of leaders (e.g. management engagement and commitment) and the importance of operational infrastructure (e.g. training programmes and reward and recognition systems). Second, the findings can help to stage and tailor improvement activities in an established setting. They provide valuable insights to support team leaders to facilitate lean integration strategies. They can also help managers to re-allocate their resources to sustain resource efficiency and increase the possibility that lean practices are implemented effectively and successfully in their organisation.

\subsection{Limitations and future research}

The results of this study offer clear indications to managers and researchers on how leadership, empowerment and culture are implemented in practice, highlighting where the emphasis is placed and identifying several challenges. However, as with all studies, some limitations should be noted, along with directions for future research.

The goal of the study was to uncover deep insights into a specific phenomenon (i.e. factors important to lean implementation) in a specific context (i.e. manufacturing organisation). Therefore, a comprehensive case study analysis was used. The advantages of the case study method lie in its applicability to understanding contemporary, social-technical systems and 
were considered to be best suited to this particular study. While this approach is useful to present a detailed contextual analysis of a limited number of factors regarding lean implementation, it is acknowledged that this approach limits the generalisability of the results. The findings from case study analyses relate directly to everyday experience and facilitate an understanding of complex real-world situations. The method of generalisation is, therefore, analytical generalisation rather than statistical generalisation, where according to Rowley (2002) previously developed theory is used as a template to compare the empirical results of the case study. Here best-practice items are presented for analytic clarity and convenience rather than as an ontological separation. Therefore, future studies can make a valuable contribution by examining the CSFs from a wider variety of contexts. As the scale used in this current study was found to be valid and reliable it, therefore, could be deployed to a larger sample from different contexts. This would facilitate a deeper comparative analysis and be helpful to advance this research area.

This study examined complex social constructs by reducing them to several quantitative scale items. However, it is acknowledged that this approach might neglect other possible antecedents and determinants that influence lean adoption. Moreover, our findings indicate that leadership, empowerment and culture are not emphasised equally by team leaders and that different functions have different perspectives on each of these constructs. Therefore, further in-depth analysis of each of these factors is required to truly understand how they impact team leaders in different functional settings and how managers could better consider the unique concerns and perspectives of this demographic as they strive to implement lean.

Finally, the results of this study demonstrated a general reluctance to lean by senior management. It would be an interesting and potentially quite valuable endeavour to study this key leadership group to obtain an understanding of the possible mental barriers that exist in terms of lean philosophy adoption. A multilevel analysis comprising various hierarchal samples might lead to some intriguing results.

\section{Conclusion}

The challenge of transitioning from a traditional manufacturing model to one that uses lean principles is incredibly complex and arduous. There are two overarching elements related to this endeavour: the "hard" elements that are processed and procedural based, as well as the "soft" elements that are managerial and culturally based. The focus of this study was on the soft elements, deciphering the intangibles and ultimately investigating how team leaders executed them when implementing lean methodologies at the critical manufacturing level.

This study was designed to redress some of the problems surrounding lean implementation and provide explanatory, context-specific empirical data on key organisational and managerial factors important to lean implementation. The research focussed on team leaders based in engineering, quality and manufacturing in a single site manufacturing facility. This research has identified leadership, empowerment and culture as salient CSFs that affect functional team leaders working at the coalface in manufacturing. Consequently, a data collection instrument was designed with these factors in mind and team leaders were asked to reflect on how elements of leadership, empowerment and culture play a part in their contributions to the successful implementation of lean. The findings indicate that many factors relating to leadership and employee empowerment were implemented by team leaders. Functional team leaders predominantly demonstrated positive attitudes towards the ideologies and benefits of lean and how it can enable their teams to achieve their goals. However, these results were not uniform across the functional groups suggesting that different factors are important for different cohorts. The manufacturing group highlighted a lack of recognition, support, incentives, as well as a
Team leaders implement lean success factors

271 
IJLSS

13,2

dearth of senior management communication and commitment. At the same time, all participants noted that there were many challenges relating to cultural factors in the organisation that needs to be rectified. This study illuminates a latent gap in commitment and communication from senior management, as well as an underlying discrepancy in time and resource allocation to support lean endeavours. This points to the need for further commitment from senior management to those leaders at a local level. The results provide valuable insights to management concerning how to support this key demographic to facilitate future lean integration strategies so that lean can become a philosophy, rather than a tools-based improvement programme.

\section{References}

Abu Bakar, F.A., Subari, K. and Mohd Daril, M.A. (2015), "Critical success factors of lean six sigma deployment: a current review”, International Journal of Lean Six Sigma, Vol. 6 No. 4, pp. 339-348.

Ahmad, S.A.S., Wan, K. and Wan, I. (2017), "Lean manufacturing, culture, lean culture", Journal of Business and Management, Vol. 1, pp. 6-14.

Aij, K.H. and Teunissen, M. (2017), "Lean leadership attributes: a systematic review of the literature", Journal of Health Organization and Management, Vol. 31 Nos 7/8, pp. 713-729.

Aij, K.H. and Rapsaniotis, S. (2017), "Leadership requirements for lean versus servant leadership in health care: a systematic review of the literature", Journal of Healthcare Leadership, Vol. 9, pp. 1-14.

Alagaraja, M. and Egan, T. (2013), "The strategic value of HRD in lean strategy implementation”, Human Resource Development Quarterly, Vol. 24 No. 1, pp. 1-27.

Al-Balushi, S., Sohal, A.S., Singh, P.J., Al Hajri, A., Al Farsi, Y.M. and Al Abri, R. (2014), "Readiness factors for lean implementation in healthcare settings - a literature review", Journal of Health Organization and Management, Vol. 28 No. 2, pp. 135-153.

Albliwi, S., Antony, J., Lim, S.A.H. and van der Wiele, T. (2014), "Critical failure factors of lean six sigma: a systematic literature review", International Journal of Quality and Reliability Management, Vol. 31 No. 9, pp. 1012-1030.

Albrecht, S.L. and Andreetta, M. (2011), "The influence of empowering leadership, empowerment and engagement on affective commitment and turnover intentions in community health service workers: test of a model", Leadership in Health Services, Vol. 24 No. 3, pp. 228-237.

Antony, J. and Gupta, S. (2019), "Top ten reasons for process improvement project failures", International Journal of Lean Six Sigma, Vol. 10 No. 1, pp. 367-374.

Antony, J., Setijono, D. and Dahlgaard, J.J. (2014), "Lean six sigma and innovation - an exploratory study among UK organizations", Total Quality Management and Business Excellence, Vol. 27 Nos 1/2, pp. 124-140.

Antony, J., Downey-Ennis, K., Antony, F. and Seow, C. (2007), "Can six sigma be the 'cure' for our 'ailing' NHS?”, Leadership in Health Services, Vol. 20 No. 4, pp. 242-253.

Assen, M.F. (2016), "Exploring the impact of higher management's leadership styles on lean management", Total Quality Management and Business Excellence, Vol. 24 Nos 7/8, pp. 1-30.

Bellisario, A. and Pavlov, A. (2018), "Performance management practices in lean manufacturing organizations: a systematic review of research evidence", Production Planning and Control, Vol. 29 No. 5, pp. 367-385.

Berg, M. and Black, G. (2014), "A Canadian perspective on clinical governance”, Clinical Governance: An International Journal, Vol. 19 No. 4, pp. 314-321.

Bhasin, S. (2012), “An appropriate change strategy for lean success”, Management Decision, Vol. 50 No. 3, pp. 439-458. 
Bortolotti, T., Boscari, S. and Danese, P. (2015), "Successful lean implementation: organizational culture and soft lean practices", International Journal of Production Economics, Vol. 160 No. 10, pp. 182-201.

Coetzee, R., Van Dyk, L. and Van der Merwe, K.R. (2019), "Towards addressing respect for people during lean implementation”, International Journal of Lean Six Sigma, Vol. 10 No. 3, pp. 830-854.

Cormican, K. and O'Sullivan, D. (2004), "Auditing best practice for effective for product innovation management”, Technovation, Vol. 24 No. 10, pp. 819-829.

Corry, S. and Cormican, K. (2019), "Towards innovation in multinational corporation subsidiaries: development of an instrument to select and evaluate value driven strategies", Journal of Technology Management and Innovation, Vol. 14 No. 1, pp. 25-33.

Delgado, C., Ferreira, M. and Branco, M.C. (2010), "The implementation of lean six sigma in financial services organizations", Journal of Manufacturing Technology Management, Vol. 21 No. 4, pp. 512-523.

DeVellis, R.F. (2012), “Scale Development: Theory and Applications, Sage publications.

Dombrowski, U. and Mielke, T. (2013), "Lean leadership - fundamental principles and their application”, Procedia CIRP, Vol. 7, pp. 569-574.

Duarte, B., Montgomery, D., Fowler, J. and Konopka, J. (2012), "Deploying LSS in a global enterprise project identification", International Journal of Lean Six Sigma, Vol. 3 No. 3, pp. 187-205.

Emiliani, M.L. and Stec, D.J. (2004), "Using value-stream maps to improve leadership", Leadership and Organization Development Journal, Vol. 25 No. 8, pp. 622-645.

Fullerton, R.R. and McWatters, C.S. (2002), "The role of performance measures and incentive systems in relation to the degree of JIT implementation”, Accounting, Organizations and Society, Vol. 27 No. 8, pp. 711-735.

Fullerton, R.R., Kennedy, F.A. and Widener, S.K. (2014), "Lean manufacturing and firm performance: the incremental contribution of lean management accounting practices", Journal of Operations Management, Vol. 32 Nos 7/8, pp. 414-428.

Gurumurthy, A. and Kodali, R. (2009), "Application of benchmarking for assessing the lean manufacturing implementation”, Benchmarking: An International Journal, Vol. 16 No. 2, pp. 274-308.

Hernandez-Matias, J.C., Ocampo, J.R., Hidalgo, A. and Vizan, A. (2019), "Lean manufacturing and operational performance: interrelationships between human-related lean practices", Journal of Manufacturing Technology Management, Vol. 31 No. 2, pp. 217-235.

Hines, P., Holweg, M. and Rich, N. (2004), "Learning to evolve: a review of contemporary lean thinking”, International Journal of Operations and Production Management, Vol. 24 No. 10, pp. 994-1011.

Hu, Q., Mason, R., Williams, S.J. and Found, P. (2015), "Lean implementation within SMEs: a literature review”, Journal of Manufacturing Technology Management, Vol. 26 No. 7, pp. 980-2012.

Hung, Y.C., Huang, S.M. and Lin, Q.P. (2005), "Critical factors in adopting a knowledge management system for the pharmaceutical industry", Industrial Management and Data Systems, Vol. 105 No. 2, pp. 164-183.

Jadhav, J.R., Mantha, S.S. and Rane, S.B. (2014), "Exploring barriers in lean implementation", International Journal of Lean Six Sigma, Vol. 5 No. 2, pp. 122-148.

Jayaram, J., Vickery, S. and Droge, C. (2008), "Relationship building, lean strategy and firm performance: an exploratory study in the automotive supplier industry", International Journal of Production Research, Vol. 46 No. 20, pp. 5633-5649.

Jeyaraman, K. and Kee Teo, L. (2010), "A conceptual framework for critical success factors of lean six sigma: implementation on the performance of electronic manufacturing service industry", International Journal of Lean Six Sigma, Vol. 1 No. 3, pp. 191-215.

Knol, W.H., Slomp, J., Schouteten, R.L. and Lauche, K. (2018), "Implementing lean practices in manufacturing SMEs: testing critical success factors using necessary condition analysis", International Journal of Production Research, Vol. 56 No. 11, pp. 3955-3973.
Team leaders implement lean success factors 
IJLSS

13,2

Laureani, A. and Antony, J. (2017), "Leadership characteristics for lean six sigma”, Total Quality Management and Business Excellence, Vol. 28 Nos 3/4, pp. 405-426.

Laureani, A. and Antony, J. (2019), "Leadership and lean six sigma: a systematic literature review", Total Quality Management and Business Excellence, Vol. 30 Nos 1/2, pp. 53-81.

Losonci, D., Kása, R., Demeter, K., Heidrich, B. and Jenei, I. (2017), "The impact of shop floor culture and subculture on lean production practices", International Journal of Operations and Production Management, Vol. 37 No. 2, pp. 205-225.

Melton, T. (2005), "The benefits of lean manufacturing: what lean thinking has to offer the process industries", Chemical Engineering Research and Design, Vol. 83 No. 6, pp. 662-673.

Möldner, A.K., Garza-Reyes, J.A. and Kumar, V. (2020), "Exploring lean manufacturing practices' influence on process innovation performance", Journal of Business Research, Vol. 106, pp. 233-249.

Mostafa, S., Dumrak, J. and Soltan, H. (2013), “A framework for lean manufacturing implementation”, Production and Manufacturing Research, Vol. 1 No. 1, pp. 44-64.

Moyano-Fuentes, J. and Sacristan-Diaz, M. (2012), "Learning on lean: a review of thinking and research", International Journal of Operations and Production Management, Vol. 32 No. 5, pp. $551-582$.

Netland, T.H. (2016), "Critical success factors for implementing lean production: the effect of contingencies", International Journal of Production Research, Vol. 54 No. 8, pp. 2433-2448.

Netland, T.H., Powell, D.J. and Hines, P. (2019), "Demystifying lean leadership”, International Journal of Lean Six Sigma, Vol. 11 No. 3, pp. 543-554.

Nguyen, N.T.D. and Chinh, N.Q. (2017), "Exploring critical factors for successfully implementing lean manufacturing at manufacturing companies in Vietnam", International Journal of Quality Research, Vol. 11 No. 2, pp. 437-456.

Pamfilie, R., Petcu, A.J. and Draghici, M. (2012), “The importance of leadership in driving a strategic lean six sigma management", Procedia - Social and Behavioral Sciences, Vol. 58, pp. 187-196.

Pepper, M.P.J. and Spedding, T.A. (2010), "The evolution of lean six sigma”, International Journal of Quality and Reliability Management, Vol. 27 No. 2, pp. 138-155.

Psychogios, A.G., Atanasovski, J. and Tsironis, L.K. (2012), "Lean six sigma in a service context: a multi-factor application approach in the telecommunications industry", International Journal of Quality and Reliability Management, Vol. 29 No. 1, pp. 122-139.

Roslin, E.N., Ahmed, S., Ahamat, M.A., Bahrom, M.Z. and Ibrahim, N. (2018), “The impact of employee involvement and empowerment in lean manufacturing system implementation towards organizational performances", International Journal on Advanced Science, Engineering and Information Technology, Vol. 9 No. 1, pp. 188-193.

Rowley, J. (2002), “Using case studies in research”, Management Research News, Vol. 25 No. 1, pp. 16-27.

Scherrer-Rathje, M., Boyle, T.A. and Deflorin, P. (2009), "Lean, take two! Reflections from the second attempt at lean implementation”, Business Horizons, Vol. 52 No. 1, pp. 79-88.

Seidel, A. and Saurin, T.A. (2020), "A framework for analyzing how context influences lean leadership”, International Journal of Lean Six Sigma, Vol. 12 No. 2, pp. 149-174.

Seidel, A., Saurin, T.A., Marodin, G.A. and Ribeiro, J.L.D. (2017), "Lean leadership competencies: a multi-method study", Management Decision, Vol. 55 No. 10, pp. 2163-2180.

Seidel, A., Saurin, T.A., Tortorella, G.L. and Marodin, G.A. (2019), "How can general leadership theories help to expand the knowledge of lean leadership?", Production Planning and Control, Vol. 30 No. 16, pp. 1322-1336.

Sreedharan, V.R., Pattusamy, M., Mohan, S. and Persis, D.J. (2020), "A systematic literature review of lean six sigma in financial services: key finding and analysis", International Journal of Business Excellence, Vol. 21 No. 3, pp. 331-358. 
Taherimashhadi, M. and Ribas, I. (2018), “A model to align the organizational culture to lean”, Journal of Industrial Engineering and Management, Vol. 11 No. 2, pp. 207-221.

Timans, W., Antony, J., Ahaus, K. and van Solingen, R. (2012), "Implementation of lean six sigma in small-and medium-sized manufacturing enterprises in The Netherlands", Journal of the Operational Research Society, Vol. 63 No. 3, pp. 339-353.

Toma, S.G. and Naruo, S. (2017), "Total quality management and business excellence: the best practices at toyota motor corporation", Amfiteatru Economic, Vol. 19 No. 45, p. 566.

Tortorella, G. and Fogliatto, F. (2017), "Implementation of lean manufacturing and situational leadership styles: an empirical study", Leadership and Organization Development Journal, Vol. 38 No. 7, pp. 946-968.

Tortorella, G.L., de Castro Fettermann, D., Frank, A. and Marodin, G. (2018), "Lean manufacturing implementation: leadership styles and contextual variables", International Journal of Operations and Production Management, Vol. 38 No. 5, pp. 1205-1227.

Van Dun, D.H., Hicks, J.N. and Wilderom, C.P.M. (2016), "Values and behaviors of effective lean managers: mixed-methods exploratory research", European Management Journal, Vol. 35 No. 2, pp. 174-186.

Vinodh, S. and Joy, D. (2012), "Structural equation modelling of lean manufacturing practices", International Journal of Production Research, Vol. 50 No. 6, pp. 1598-1607.

Vlachos, I.P. (2014), "A hierarchical model of the impact of RFID practices on retail supply chain performance”, Expert Systems with Applications, Vol. 41 No. 1, pp. 5-15.

Yadav, G. and Desai, T.N. (2016), "Lean six sigma: a categorized review of the literature", International Journal of Lean Six Sigma, Vol. 7 No. 1, pp. 2-24.

Yadav, G. and Desai, T.N. (2017), "Analyzing lean six sigma enablers: a hybrid ISM-fuzzy MICMAC approach", The TQM Journal, Vol. 29 No. 3, pp. 488-511.

Yadav, G., Seth, D. and Desai, T.N. (2017), "Analysis of research trends and constructs in context to lean six sigma frameworks", Journal of Manufacturing Technology Management, Vol. 28 No. 6, pp. $794-821$.

\section{Corresponding author}

Kathryn Cormican can be contacted at: kathryn.cormican@nuigalway.ie
Team leaders implement lean success factors

For instructions on how to order reprints of this article, please visit our website:

www.emeraldgrouppublishing.com/licensing/reprints.htm

Or contact us for further details: permissions@emeraldinsight.com 